\title{
Comparison of the pupillary, refractive, and hypotensive effects of Ocusert-40 and pilocarpine eyedrops in the treatment of chronic simple glaucoma
}

\author{
S. E. SMITH, SHIRLEY A. SMITH, A. I. FRIEDMANN, AND \\ JENNIFER M. CHASTON \\ From the Departments of Pharmacology and Ophthalmology, St. Thomas's Hospital and Medical School, \\ and the Royal Eye Hospital, London
}

SUMMARY Twelve patients with chronic simple glaucoma were treated for 1 week with Ocusert-40, and the effects on the pupil, intraocular pressure, and refraction were measured. A comparison was made with the effects of pilocarpine eyedrop therapy in 8 of these patients. Both forms of pilocarpine treatment gave satisfactory control of intraocular pressure and both constricted the pupil to a similar degree shortly after initiation of treatment. During the week on Ocusert-40 the pupils redilated, so that $54 \%$ of the initial miosis remained after 7 days' wear. There was, however, considerable variability in the pupillary sensitivity to Ocusert- 40 within and between eyes, and it is suggested that this may have been partly due to variable release rates of pilocarpine. Only minor decreases in visual acuity and refraction resulted from pilocarpine in either form. Seven of the 12 patients rejected Ocusert- 40 because of discomfort or inability to retain the device.

Pilocarpine eyedrops have been widely prescribed for glaucoma for many years despite two major disadvantages. Firstly, they need to be instilled 3 or 4 times daily, which encourages non-compliance (Vincent, 1971), with the consequent risk of inadequate pressure control. Secondly, the drops deliver a large dose which initially causes side effects of browache, darkening of vision due to pupillary constriction, and myopia. Ocuserts appear to offer a promising alternative to conventional drop therapy because their continuous release of lower drug concentrations has been reported to cause relatively few side effects while adequately controlling pressure (Brown et al., 1976; Drance et al., 1977; Hillman et al., 1977). This study was designed to confirm these reports by comparing the pupillary, refractive, and ocular hypotensive effects of Ocusert40 with conventional drop therapy in a group of glaucoma patients.

\section{Patients and methods}

\section{PATIENTS}

Twelve patients with bilateral chronic simple glaucoma volunteered for the study. Four of them

Address for reprints: Dr S. E. Smith, Department of Pharmacology, St. Thomas's Hospital Medical School, London SE1 7EH were recently diagnosed and untreated cases and 8 had been treated previously with pilocarpine eyedrops only, for periods that varied from 1 week to 6 years. Details of the patients and their treatments are given in Table 1. All oral treatments for other diseases remained unchanged throughout the period of study.

\section{TREATMENTS}

The investigation had a total duration of 15 days (Fig. 1). Only patients 1-8, previously treated with pilocarpine eyedrops, completed the whole study; the remaining 4 patients entered at day 8 . On day 1 the patients were given their final application of drops and the effects were noted. Pilocarpine treatment was then stopped and dummy Ocuserts were inserted to familiarise the patient with this type of treatment. The patient was unaware that the Ocuserts were drug-free. The dummies were worn for 1 week, during which time no pilocarpine was given, but treatment was continued with oral acetazolamide (Diamox Sustets $500 \mathrm{mg}$ twice daily). On day 8 the acetazolamide was stopped and the dummy Ocuserts were replaced by Ocusert-40 systems (May \& Baker Ltd.), which in the steady state release pilocarpine at a rate of $40 \mu \mathrm{g} / \mathrm{h}$. These were also worn for 1 week, after which the patients were given the choice of drops or Ocuserts for continuation of therapy. 
Table 1 Details of patients

\begin{tabular}{|c|c|c|c|c|c|c|}
\hline \multirow[b]{2}{*}{ No. } & \multirow[b]{2}{*}{ Age } & \multirow[b]{2}{*}{ Sex } & \multirow[b]{2}{*}{ Race } & \multicolumn{2}{|c|}{ Previous pilocarpine eyedrop treatment } & \multirow{2}{*}{$\begin{array}{l}\text { Other drug treatments } \\
\text { (oral administration) }\end{array}$} \\
\hline & & & & Concentration (\%) & Duration & \\
\hline 1 & 68 & Male & Caucasian & 4 & 2 weeks & $\begin{array}{l}\text { Propranolol } 20 \mathrm{mg} 3 \text { times a day } \\
\text { Glyceryl trinitrate as required }\end{array}$ \\
\hline 2 & 70 & Female & Asian & 4 & 2 weeks & - \\
\hline 3 & 54 & Male & Caucasian & 1 & 6 years & - \\
\hline 4 & 56 & Male & Caucasian & 2 & 18 months & Propranolol $40 \mathrm{mg} 3$ times a day \\
\hline 5 & 62 & Female & Caucasian & 4 & 1 week & - \\
\hline 6 & 67 & Male & Caucasian & 2 & 9 months & 一 \\
\hline 7 & 51 & Female & Negro & 4 & 1 week & $\begin{array}{l}\text { Timolol } 10 \mathrm{mg} 4 \text { times a day } \\
\text { Methyldopa } 500 \mathrm{mg} 3 \text { times a day }\end{array}$ \\
\hline 8 & 65 & Male & Caucasian & 2 & 2 weeks & $\begin{array}{l}\text { Acebutolol } 100 \mathrm{mg} 4 \text { times a day } \\
\text { Prazosin } 2 \mathrm{mg} 3 \text { times a day } \\
\text { Chlorpropamide } 100 \mathrm{mg} \text { once daily }\end{array}$ \\
\hline 9 & 47 & Female & Caucasian & - & - & $\begin{array}{l}\text { Acetazolamide (Sustet) } 500 \mathrm{mg} \text { twice daily } \\
\text { (stopped during study) }\end{array}$ \\
\hline 10 & 49 & Male & Caucasian & - & - & - \\
\hline 11 & 76 & Female & Caucasian & - & - & $\begin{array}{l}\text { Cyclopenthiazide } 0.5 \mathrm{mg} \text { once daily } \\
\text { Diazepam } 2 \mathrm{mg} \text { once daily }\end{array}$ \\
\hline 12 & 56 & Female & Caucasian & - & - & - \\
\hline
\end{tabular}

Fig. 1 Design of experiment showing when pupil (P), intraocular pressure (IOP), and refraction $(R)$ meaurements were performed

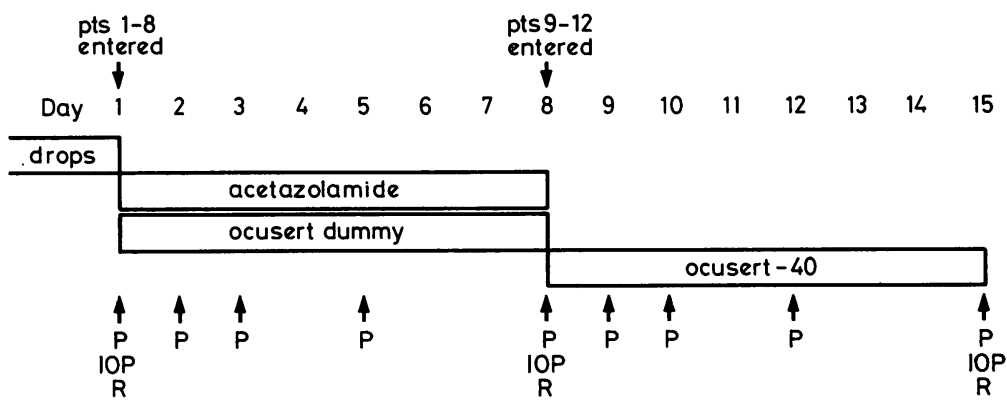

Most patients preferred to wear the Ocuserts in the upper fornix.

\section{MEASUREMENTS}

The intraocular pressure (IOP), resting pupil diameter, visual acuity, and refraction were measured for both eyes on the days indicated. IOP was measured by applanation tonometry under local anaesthesia with benoxinate $0.4 \%$. Three readings were recorded from each eye, the tonometer dial being read and reset by an independent observer. Resting pupil diameters were recorded in darkness with a Whittaker Series 1800 infrared television pupillometer (Smith et al., 1978). Visual acuity was measured at $5 \mathrm{~m}$ with a 5-m Snellen chart. Changes induced by pilocarpine were related to baseline values for visual acuity and refraction, which for patients 1 to 8 were the readings taken 5 to 6 hours after their last drops on day 1 and for patients 9 to 12 were those taken before Ocusert treatment on day 8 . Refraction was found objectively by retinoscopy when possible and subjectively by the use of a duochrome Snellen chart.

\section{Results}

INTRAOCULAR PRESSURE

The IOP (mean \pm standard error) in the 16 eyes from 8 patients previously treated with drops was $21 \cdot 3 \pm 0.7, \quad 18.5 \pm 0.9$, and $21 \cdot 2 \pm 0.6 \mathrm{mmHg}$ after eyedrops, acetazolamide, and Ocusert therapy respectively. Whereas all 3 treatments gave satis- 
factory control, the pressure after acetazolamide was significantly lower $(\mathrm{P}<0.001)$ than after either form of pilocarpine treatment. In the 4 patients who had not previously received eyedrops the mean IOP was $25.5 \pm 2.3$ and $19.6 \pm 1.2 \mathrm{mmHg}$ before and after Ocusert treatment respectively.

PUPIL RESPONSES

Recovery of the pupil diameter after cessation of eyedrop therapy was complete in 2 to 4 days. After insertion of Ocusert-40 the mean diameter fell from 5.23 to $1.93 \mathrm{~mm}$ at 1 hour. During the following week (Fig. 2) the pupils gradually recovered to a final mean size of $3.45 \mathrm{~mm}$ on day 15 . Thus $54 \%$ of the maximum miotic effect of Ocusert-40 remained at the end of the week.

In patients 1 to 8 the peak effect of Ocusert-40 was compared with that resulting from 1 drop of pilocarpine at the concentration prescribed for each individual (see Table 1). No difference was found in the size of the pupil at the maximum effect of each treatment $(1.70 \mathrm{~mm}$ after drops and $1.63 \mathrm{~mm}$ after Ocusert). In the Caucasian patients peak effects occurred at approximately 40 minutes after drops and 1 hour after Ocusert insertion, but in the Asian and Negro patients the time course of both pilocarpine treatments was delayed. Thus the peak effect of Ocusert in the 2 non-white patients was measured on day 9 at a time when the pupils of all the white patients were recovering.

There was considerable variability in the pupillary response to Ocusert-40, illustrated by the two extremes in Fig. 3. The left pupil of patient 10 had recovered completely by the end of the week, and

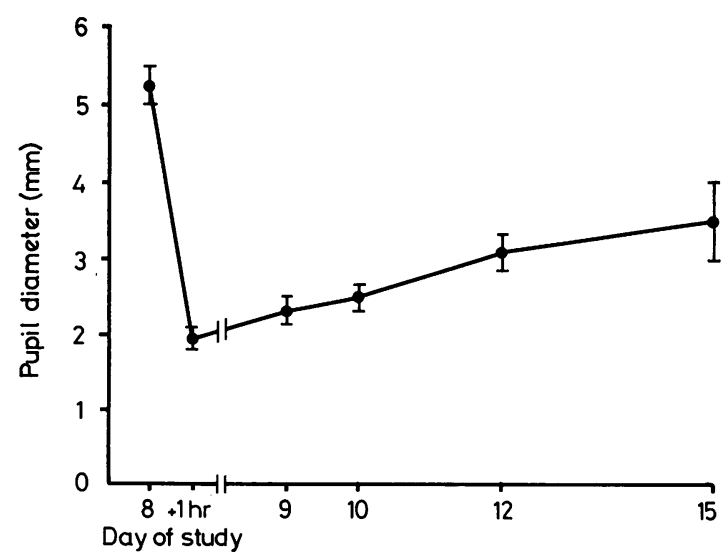

Fig. 2 Pupil diameters in 12 patients treated with Ocusert-40. Data for day 8 show the diameter before and 1 hour after insertion. Three eyes were unsuitable for television pupillometry, hence the mean and standard errors shown are from 21 eyes

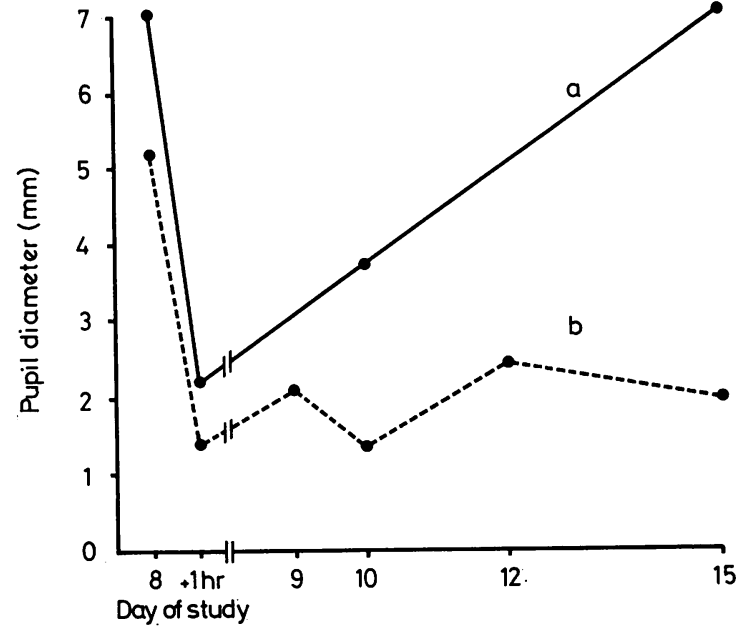

Fig. 3 The pupil size in (a) patient 10, left eye; and (b) patient 9 , right eye during Ocusert-40 treatment illustrates the variability in pupillary response

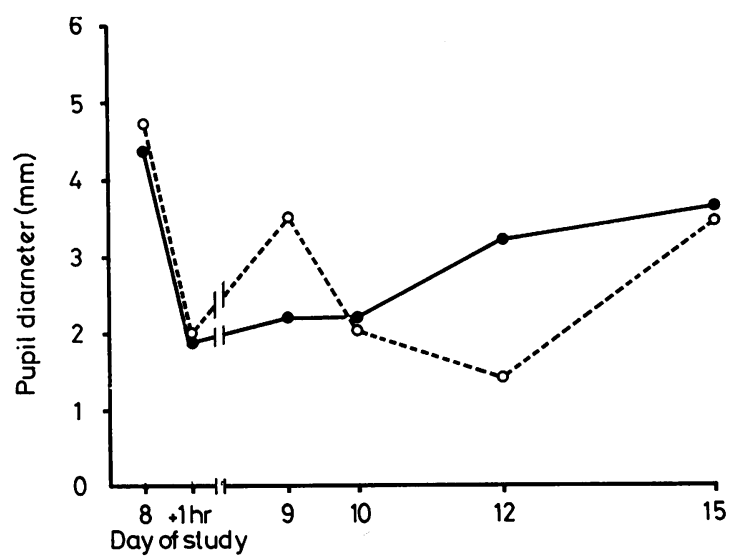

Fig. 4 The pupillary response of the left $(0)$ and right $(O)$ eyes of patient 5 during Ocusert-40 treatment. On day 12 there was an intense miosis in the right eye, which was red and sore

this corresponded with a poor response of IOP. Pressures before and after Ocusert were 39 and 29 $\mathrm{mmHg}$ respectively compared with 47 and $14 \mathrm{mmHg}$ respectively in the right eye which retained a pupillary effect. In contrast, the pupil of the right eye of patient 9, in which the pressure response was good, was still tightly constricted on day 15 .

Fig. 4 illustrates a phenomenon encountered in 5 of the 12 patients during the week with Ocusert-40 treatment. On day 12 this patient complained of soreness in his right eye, which had conjunctival 
injection and a pupil that had reconstricted to a very small size $(1.37 \mathrm{~mm})$. Within the group these reconstrictions, which interrupted the gradual pupillary redilatation, were always accompanied by complaints of discomfort and occurred most frequently in the second half of the week. This phenomenon did not occur once in the 8 patients who wore dummy Ocuserts for 1 week.

\section{VISUAL ACUITY AND REFRACTION}

In all patients studied only small changes were induced by pilocarpine given in drops or Ocuserts with mean values not exceeding a 1-line decrease in Snellen visual acuity and a $0.5 \mathrm{D}$ myopic shift in refraction. The only marked pilocarpine effect was in patient 3, whose myopia increased by $1.5 \mathrm{D}$ during the first hour after both drops and Ocusert-40. By the end of the week on Ocusert- 40 his refraction had returned to its baseline value.

PATIENT ACCEPTABILITY

Patients were followed-up 1 to 3 months after completion of the study to check on the type of therapy they preferred. It was found that only 5 of the 12 were still using Ocuserts, the remainder having reverted to drops. The reasons for the failures were invariably given as 'discomfort' or that the Ocuserts 'kept falling out'.

\section{Discussion}

In confirmation of previous reports it was found that IOP was adequately controlled by Ocusert- 40 therapy. The mean level of pressure was identical after pilocarpine in either delivery form, but acetazolamide gave a significantly better response. However, all the patients disliked the tingling sensation in the skin that accompanied acetazolamide therapy.

It has been reported that Ocusert-40 treatment is relatively free of the pupillary and refractive side effects of pilocarpine eyedrops (Brown et al., 1976). The results of this study, however, show that shortly after pilocarpine was given in either form the pupil constricted to a size that probably represented its physical minimum diameter. Although the peak effects were thus comparable, with Ocuserts the pupils redilated, so that only half the initial miosis remained at the end of the week. Thus despite the unexpected pupillary constrictions that interrupted the course of this redilatation in some patients (Fig. 4), in general patients avoided the repeated fluctuations that occur with drop therapy.

Reports that Ocuserts affect visual acuity and refraction less than drops (Hillman et al., 1977; Drance et al., 1977) are not supported by this study, since here only minor changes were induced by both forms of pilocarpine. This was probably because all our patients were aged over 40 years, and, as noted previously, pilocarpine-induced myopia is rare in the older age group (Hitchings and Smith, 1977). Claims that Ocuserts have marked visual benefits based on studies with young normal subjects (Place et al., 1975) are therefore of limited relevance, since the majority of patients with simple glaucoma are elderly.

Five of the 12 patients that received Ocusert- 40 treatment experienced the phenomenon illustrated in Fig. 4 in which the pupil reconstricted to its minimum size and the conjunctiva became red and uncomfortable. As this phenomenon did not occur with the drug-free Ocuserts, it was presumably caused by a sudden leakage of pilocarpine in excess of the 'controlled' release rate. Such phenomena have been observed before (Lee et al., 1975), though less frequently than in this study, probably because our patients were examined more often (on 5 of 8 days of treatment). The release of pilocarpine from Ocusert-40 may therefore be less predictable than is claimed by the manufacturers. Variability in release rates of individual Ocusert-40 systems may also have contributed to the differences in pupillary sensitivity in this group of patients.

Only 5 of the 12 patients who entered the study chose to continue with Ocusert-40 treatment. Other workers have reported similar drop-out rates (Hitchings and Smith, 1977; Hillman et al., 1977). Some of our patients reverted to drops because they found Ocuserts uncomfortable to wear, and some of the more elderly had difficulty in retaining them under lax eyelids.

It is concluded that some patients, particularly younger ones, may benefit from a reduction in side effects when pilocarpine is administered in the form of Ocusert-40. However, the possibility that the drug release rate may suddenly increase needs further investigation.

One of the authors (S. A. S.) was in receipt of a Research Fellowship from the Medical Research Council. The Ocuserts and financial support were kindly provided by May \& Baker Ltd.

\section{References}

Brown, H. S., Meltzer, G., Merrill, R. C., Fisher, M., Ferré, C., and Place, V. A. (1976). Visual effects of pilocarpine in glaucoma. Comparative study of administration by eyedrops or by ocular therapeutic systems. Archives of Ophthalmology, 94, 1716-1719.

Drance, S. M., Mitchell. D. W. A., and Schultzer, M. (1977). The effects of Ocusert pilocarpine on anterior chamber depth, visual acuity and intraocular pressure in man. Canadian Journal of Ophthalmology, 12, 24-28.

Hillman, J. S. Walker, A., and Davies, E. M. (1977). The 
management of chronic glaucoma with pilocarpine Ocusert. Transactions of the Ophthalmological Societies of the United Kingdom, 97, 206-209.

Hitchings, R. A., and Smith, R. J. H. (1977). Experience with pilocarpine Ocuserts. Transactions of the Ophthalmological Societies of the United Kingdom, 97, 202-205.

Lee, P., Shen, Y. T., and Eberle, M. (1975). The long-acting Ocusert-pilocarpine system in the management of glaucoma. Investigative Ophthalmology, 14, 43-46.

Place, V. A., Fisher, M., Herbst, S., Gordon, L., and
Merrill, R. C. (1975). Comparative pharmacological effects of pilocarpine administered to normal subjects by eyedrops or by ocular therapeutic systems. American Journal of Ophthalmology, 80, 706-712.

Smith, S. A., Smith, S. E., and Lazare, R. (1978). An increased effect of pilocarpine on the pupil by application of the drug in oil. British Journal of Ophthalmology 62, 314-317.

Vincent, P. (1971). Factors influencing patient noncompliance: a theoretical approach. Nursing Research, 20 , 509-516. 